Article

\title{
Nanoparticles Dual Targeting Both Myeloma Cells and Cancer-Associated Fibroblasts Simultaneously to Improve Multiple Myeloma Treatment
}

\author{
Honglan Wang ${ }^{1,+}$, Huiwen Liu ${ }^{1,+}$, Chunyan Sun ${ }^{1,+}$, Chunying Liu ${ }^{2}$, Ting Jiang ${ }^{1}$, Yanxue Yin ${ }^{1}$, Aoshuang Xu ${ }^{1}$, \\ Zhiqing Pang ${ }^{2, *(\mathbb{D} \text {, Bo Zhang }}{ }^{1, *}$ and $\mathrm{Yu} \mathrm{Hu}{ }^{1, *}$
}

1 Institute of Hematology, Union Hospital, Tongji Medical College, Huazhong University of Science \& Technology, Wuhan 430022, China; d201881377@hust.edu.cn (H.W.); m201975631@hust.edu.cn (H.L.); 2006xh0838@hust.edu.cn (C.S.); 2018xh0213@hust.edu.cn (T.J.); 2018xh0215@hust.edu.cn (Y.Y.); xasjoanna@hust.edu.cn (A.X.)

2 Key Laboratory of Smart Drug Delivery, Ministry of Education, School of Pharmacy, Fudan University, 826 Zhangheng Road, Shanghai 201203, China; 19211030014@fudan.edu.cn

* Correspondence: zqpang@fudan.edu.cn (Z.P.); 2015xh0829@hust.edu.cn (B.Z.); 1988xh0506@hust.edu.cn (Y.H.); Tel.: +86-21-51980069 (Z.P.); +86-27-85726007 (B.Z.); +86-27-85726335 (Y.H.); Fax: +86-21-51980069 (Z.P.); $+86-27-85726387$ (B.Z.); $+86-27-85776343$ (Y.H.)

$+\quad$ These author contributed equally to this work.

\section{check for} updates

Citation: Wang, H.; Liu, H.; Sun, C.; Liu, C.; Jiang, T.; Yin, Y.; Xu, A.; Pang, Z.; Zhang, B.; Hu, Y. Nanoparticles Dual Targeting Both Myeloma Cells and Cancer-Associated Fibroblasts Simultaneously to Improve Multiple Myeloma Treatment. Pharmaceutics 2021, 13, 274. https://doi.org/ 10.3390/pharmaceutics13020274

Academic Editors: Yvonne Perrie and Juan Aparicio-Blanco

Received: 6 December 2020

Accepted: 10 February 2021

Published: 18 February 2021

Publisher's Note: MDPI stays neutral with regard to jurisdictional claims in published maps and institutional affiliations.

Copyright: (c) 2021 by the authors. Licensee MDPI, Basel, Switzerland. This article is an open access article distributed under the terms and conditions of the Creative Commons Attribution (CC BY) license (https:// creativecommons.org/licenses/by/ $4.0 /)$.
Abstract: Cancer-associated fibroblasts (CAFs) and myeloma cells could mutually drive myeloma progression, indicating that drug delivery to kill both CAFs and myeloma cells simultaneously could achieve better therapeutic benefits than to kill each cell type alone. Here, we designed a dual-targeting drug delivery system by conjugating paclitaxel (PTX)-loaded poly(ethylene glycol)-poly(lactic acid) nanoparticles (NPs) with a cyclic peptide (CNPs-PTX) with a special affinity with platelet-derived growth factor/platelet-derived growth factor receptor (PDGFR- $\beta$ ) overexpressed on both CAFs and myeloma cells. Cellular uptake experiments revealed that the cyclic peptide modification on CNPs could significantly enhance CNPs uptake by both CAFs and myeloma cells compared with unmodified NPs. Cytotoxicity tests showed that CNPs-PTX was more toxic to both CAFs and myeloma cells compared with its counterpart PTX-loaded conventional NPs (NPs-PTX). In vivo imaging and biodistribution experiments showed that CNPs could abundantly accumulate in tumors and were highly co-localized with CAFs and myeloma cells. The in vivo anti-tumor experiments confirmed that the anti-myeloma efficacy of CNPs-PTX was significantly stronger than that of NPsPTX and free drugs. In summary, it is the first time that a dual-targeting strategy was utilized in the field of myeloma treatment through targeting both CAFs and myeloma cells simultaneously, which harbors a high potential of clinical translation for myeloma treatment.

Keywords: multiple myeloma; CAFs; PDGFR- $\beta$; dual-targeting drug delivery; nanoparticles

\section{Introduction}

Multiple myeloma (MM), a malignancy of terminally differentiated plasma cells, is the second most common hematologic tumor. $\mathrm{MM}$ is still incurable despite exciting advances over the past few years by the application of different new strategies such as immunomodulatory drugs, proteasome inhibitors, and monoclonal antibodies, etc. [1,2]. Drug resistance and MM relapse represent a big challenge for myeloma treatment [3]. Accumulated evidence shows that the complex tumor microenvironment (TME), which serves as the soil for the myeloma cell surviving, is the main contributor to drug resistance, relapse, and progression of MM. TME and myeloma cells are always closely associated with each other and drive mutually to accelerate myeloma growth [4].

The TME of MM is mainly composed of extracellular matrix and many different types of stromal cells, including cancer-associated fibroblasts (CAFs), osteoclasts, and 
macrophages. As an important type of stromal cells in TME, CAFs have been reported to be closely related to tumor growth, metastasis, and invasion in different types of solid tumors. Some drugs targeting CAFs could modulate the TME and improve patient outcomes $[5,6]$. In MM patients, CAFs were closely associated with MM clinical stage and disease prognosis. CAFs could promote MM cell adhesion, proliferation and anti-apoptosis by secreting various cytokines and cell-to-cell interaction [7]. The interaction between CAFs and myeloma cells contributes to MM angiogenesis and progression [4], highly indicating that dual-targeting drug delivery to both CAFs (soil) and myeloma cells (seed) simultaneously could achieve a better therapeutic effect for MM treatment than targeting each cell type alone.

Nanotherapeutics could achieve a better therapeutic effect on tumors than free drugs based on the enhanced permeability and retention (EPR) effect of tumors [8,9]. However, the benefits of some anti-tumor nanotherapeutics, such as Doxil and Abraxane, two nanotherapeutics approved by the Food and Drug Administration (FDA) for use in solid tumors are still far from satisfactory $[10,11]$. As an extension, active targeting drug delivery systems, which are modified with targeting moieties holding special affinity to the corresponding antigens overexpressed in tumor tissues, have been explored to achieve additional anti-tumor efficacy compared with those based on the EPR effect alone [12,13]. Therefore, active drug delivery systems dual targeting both myeloma cells and CAFs simultaneously might achieve a strong therapeutic effect for MM treatment if suitable antigens overexpressed by both cells and corresponding targeting moieties can be selected.

Nowadays, it is widely accepted that the platelet-derived growth factor/plateletderived growth factor receptors (PDGF/PDGFR) axis is involved in tumor angiogenesis, tumor growth, and metastasis [14]. PDGFR- $\beta$ is low expressed in mesenchymal derived fibroblasts, vascular smooth muscle cells, monocytes, and other cell types under normal conditions. While in pathologic condition such as malignant tissue, PDGFR- $\beta$ expression is strikingly increased in CAFs and tumor cells such as myeloma cells [6,15]. Moreover, the expression level of PDGFR- $\beta$ is closely associated with MM angiogenesis and clinical stage [16], indicating that PDGFR- $\beta$ could serve well as the therapeutic target for the dual-targeting strategy for myeloma treatment.

In the present study, a dual-targeting drug delivery system was designed by using a cyclic peptide with high affinity to PDGFR- $\beta$ [5] as the targeting moiety, PDGFR- $\beta$ overexpressed on both myeloma cells and CAFs as the therapeutic target, nanoparticles (NPs) based on FDA-approved biodegradable poly(ethylene glycol)-poly(lactic acid) as the drug carrier, and the classical chemotherapeutics paclitaxel (PTX) as the model drug (Figure 1). The cyclic peptide-modified NPs (CNPs) were synthesized and carefully characterized. The dual-targeting property of fluorescence-labeled CNPs was investigated by cellular uptake experiments, in vivo fluorescence imaging, and co-localization studies. The anti-myeloma effect of PTX-loaded CNPs (CNPs-PTX) was explored by cell apoptosis assay in vitro and an anti-myeloma test in vivo, and compared with those of Taxol and unmodified PTX-loaded NPs (NPs-PTX). 


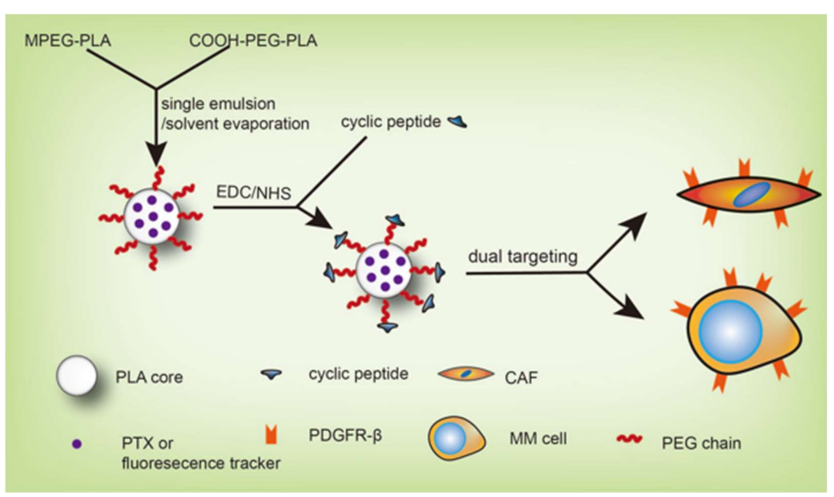

Figure 1. Schematic graph of dual-targeting drug delivery system design for myeloma treatment by targeting cancer-associated fibroblasts (CAFs) and myeloma cells simultaneously.

\section{Materials and Methods}

\subsection{Materials}

Cyclic peptide (Cys-Ser-Arg-Asn-Leu-lle-Asp-Cys (Cys\&Cys bridge)) was synthesized by the Chinese Peptide Company (China). Methoxy-poly(ethylene glycol) (MPEG, MW $3000 \mathrm{Da}$ ) was ordered from NOF (Tokyo, Japan). R-carboxyl-poly(ethylene glycol) (COOH-PEG, Mw $3400 \mathrm{Da}$ ) was purchased from Laysan Bio (Arab, AL, USA). D,LLactide (purity: 99.5\%) was from PURAC (Arkelsedijk, Holland). Methoxy-poly (ethylene glycol)-poly(lactic acid) (MPEG-PLA, Mw 33,000 Da) and R-carboxyl-poly(ethylene glycol)-poly(lactic acid) (COOH-PEG-PLA, Mw 33,400 Da) block copolymers were synthesized through ring-opening polymerization of lactide using MPEG and COOH-PEG as the initiator as previous reported [17]. Sodium cholate was purchased from Sigma (New York, NY, USA). Fluorescence tracker coumarin-6 was ordered from Sigma (New York, NY, USA). Hoechst 33342 was from Beyotime ${ }^{\circledR}$ Biotechnology Co. Ltd. (Nantong, China). 1,1'-Dioctadecyl-3,3,3', $3^{\prime}$-tetramethylindo-tricarbocyanineiodide (DiR) was from Biotium (Invitrogen, Fremont, CA, USA). 1-(3-dimethylaminopropyl)-3-ethylcarbodiimide hydrochloride (EDC-HCl) and N-hydroxy-succinimide (NHS) were ordered from Sigma (New York, NY, USA). PTX was purchased from Xi'an San jiang Bio-Engineering Co. Ltd. (Xi'an, China). CD31 rabbit polyclonal primary antibody and CD138 monoclonal primary antibody were from Abcam (Cambridge, UK). $\alpha$-Smooth muscle actin ( $\alpha$-SMA) rabbit monoclonal primary antibody was from Cell Signaling Technology (USA). Cy3-Affinipure goat anti-mouse IgG and Alexa fluor 647 Affinipure goat anti-rabbit IgG were obtained from Jackson (Philadelphia, PA, USA). The FITC (fluorescein isothiocyanate) Annexin V apoptosis detection kit I was purchased from BD Biosciences (San Jose, CA, USA). Fetal bovine serum (FBS), Newborn Calf Serum (NBCS), trypsin-EDTA (0.25\%), RPMI 1640 medium, Modified Eagle's Medium (MEM), and penicillin-streptomycin were from Gibco (Carlsbad, CA, USA). Plastic cell culture dishes were obtained from Corning Incorporation (Corning, NY, USA). Deionized water from the Millipore Simplicity System (Millipore, Bedford, MA, USA) was used throughout the entire study. All other reagents and chemicals were of analytical reagent grade and were purchased from Sinopharm Chemical Reagent (Shanghai, China).

RPMI 8226 cell lines were ordered from American Type Culture Collection. Mouse NIH-3T3 fibroblasts were ordered from the Chinese Academy of Sciences Cell Bank (Shanghai, China). They were cultured according to the recommended suggestions. Male Balb/c nude mice (six- to eight-week-old) were from the Shanghai Slac Lab Animal Ltd. (Shanghai, China). All experiments were carried out according to the regulations and standards of the ethics committee of Fudan University (approval code: 2017-03-YJ-PZQ-01,1 March 2017).

\subsection{Synthesis and Characterization of CNPs}

NPs were fabricated with a single emulsion/solvent evaporation method as previously described $[8,18]$. In a typical procedure, $1 \mathrm{~mL}$ of dichloromethane dissolving $24 \mathrm{mg}$ of 
MPEG-PLA and $1 \mathrm{mg}$ COOH-PEG-PLA was added into $5 \mathrm{~mL}$ of $0.6 \%$ sodium cholate aqueous solution and then subjected to sonication ( $200 \mathrm{~W}, 5 \mathrm{~s}$ for 15 times) in an ice bath by a probe sonicator (Scientz Biotechnology Co. Ltd., Ningbo, China). After removing dichloromethane with a ZX-98 rotary evaporator (Shanghai Institute of Organic Chemistry, China), NPs was collected by centrifuge at 14,500 rpm for $45 \mathrm{~min}$ (Thermo Biofuge Stratos, Waltham, MA, USA). CNPs was prepared by reaction of carboxyl group on the surface of NPs with an amino group on cyclic peptide with EDC/NHS method as previously reported [18]. In our study, the molar ratio of the carboxyl group to amino group is 3:1, and the mass ratio of COOH-PEG-PLA to cyclic peptide is $1 \mathrm{mg}: 20 \mu \mathrm{g}$.

Quantification of the cyclic peptide was performed by a high-performance liquid chromatography (HPLC) system (Agilent 1200 series; Santa Clara, CA, USA) equipped with an analytical column $(150 \mathrm{~mm} \times 4.6 \mathrm{~mm}$; pore size $5 \mu \mathrm{m}$; ZORBAX 300 0SB-C18; Agilent). A mixture of solvent A ( $0.1 \%$ trifluoroacetic acid in water) and solvent B ( $80 \%$ acetonitrile solution containing $0.09 \%$ trifluoroacetic acid in water) in varying proportions was used as the mobile phase. Gradient program was increased linearly from $17 \%$ mobile phase $B$ to $27 \%$ mobile phase $B$ in $20 \mathrm{~min}$ at a flow rate of $1.0 \mathrm{~mL} / \mathrm{min}$. The sample injection volume was $10 \mu \mathrm{l}$, and the detector wavelength was $220 \mathrm{~nm}$. The conjugation efficiency (CE) of cyclic peptide with NPs was calculated as follows:

$$
\mathrm{CE}=\frac{\text { cyclic peptide }_{\text {total }}-\text { cyclic peptide }_{\text {free }}}{\text { cyclic peptide }_{\text {total }}} \times 100 \%
$$

The size distribution and zeta potential of NPs and CNPs were investigated by dynamic light scattering using a Malvern Nano ZS (Malvern Instruments, UK), and the morphology was observed using transmission emission microscopy (TEM) (H-600, Hitachi, Japan) after negative stained with $2 \%$ phosphotungstic acid. The stability of NPs and CNPs were investigated by monitoring different parameters including particle size, polydispersity index (PDI), and zeta potential during one-week storage in $5 \% \mathrm{FBS}$ at $4{ }^{\circ} \mathrm{C}$.

Coumarin-6-, DiR-, and PTX-loaded NPs and CNPs were synthesized by the same method as blank NPs and CNPs except that $25 \mu \mathrm{g}$ of coumarin-6, $200 \mu \mathrm{g}$ of DiR, or $2 \mathrm{mg}$ of PTX was added into the dissolved MPEG-PLA and COOH-PEG-PLA in $1 \mathrm{~mL}$ of dichloromethane in advance.

\subsection{Characterization of CNPs-PTX}

The drug-loading capacity (LC) and encapsulation efficiency (EE) and of NPs-PTX and CNPs-PTX were investigated as previously reported [18]. In brief, NPs-PTX or CNPsPTX was dissolved in acetonitrile with the volume ratio of PTX-loaded NPs or CNPs to acetonitrile 1:9. After being vortexed for $1 \mathrm{~min}$ and centrifuged at 10,000 rpm for $10 \mathrm{~min}$, the PTX concentration in the supernatant was measured by the HPLC system, as mentioned in the cyclic peptide concentration determination part. The mobile phase was a mixture of acetonitrile and water $(\mathrm{CH} 3 \mathrm{CN}: \mathrm{H} 2 \mathrm{O}=55: 45, v / v)$ with a flow rate of $1.0 \mathrm{~mL} / \mathrm{min}$. The sample injection volume was $10 \mu \mathrm{l}$, and the detector wavelength was $227 \mathrm{~nm}$. The LC and EE were calculated using Equations (2) and (3), respectively:

$$
\begin{aligned}
\mathrm{LC} & =\frac{\mathrm{Mp}}{\mathrm{Mn}} \times 100 \% \\
\mathrm{EE} & =\frac{\mathrm{Mp}}{\mathrm{Mpt}} \times 100 \%
\end{aligned}
$$

where Mp is the amount of PTX in the NPs, Mn is the amount of NPs, and Mpt is the total amount of PTX added to the formulation.

The in vitro release behaviors of PTX from NPs-PTX and CNPs-PTX were investigated by a dialysis method [18]. Briefly, $1 \mathrm{~mL}$ of both PTX formulations with $60 \mu \mathrm{g}$ of PTX was put into a dialysis bag (MWCO 8000 Da; Green Bird Inc, Shanghai, China) and incubated in $10 \mathrm{~mL}$ of release medium $\left(0.01 \mathrm{M}, \mathrm{pH}=7.4 \mathrm{PBS}\right.$ with $0.5 \%$ Tween-80) at $37^{\circ} \mathrm{C}$ with 
the shaking speed of $120 \mathrm{rpm}$ for $48 \mathrm{~h}$. At each time point preset, $300 \mu \mathrm{l}$ of aliquot was withdrawn, and fresh release medium with an equal volume was added immediately. The amount of PTX released at different time points was measured by the same method as mentioned above.

\subsection{Cellular Uptake Experiment}

RPMI 8226 cells were seeded into a laser confocal Petri dish at a density of $5 \times 10^{5}$ cells / dish. After $24 \mathrm{~h}$ of culture, coumarin-6-labeled NPs and CNPs were added into the dish at a concentration of $20 \mathrm{ng} / \mathrm{mL}$ coumarin-6 per well and incubated at room temperature for $1 \mathrm{~h}$. For the cyclic peptide inhibition experiment, excessive free cyclic peptide $(10 \mu \mathrm{g} / \mathrm{mL})$ was added $0.5 \mathrm{~h}$ before CNPs incubation. For the PDGFR inhibition experiment, PDGFR blocking agent suramin sodium $(200 \mu \mathrm{mol} / \mathrm{L})$ was added when CNPs incubation started [19]. Cells were subsequently washed three times with cold PBS (0.01 M, pH = 7.4), fixed with $4 \%$ paraformaldehyde, and then observed under fluorescence microscopy (Leica, Wetzlar, Germany). The semi-quantitative results were obtained by ImageJ using five randomly acquired images from different fields. NIH-3T3 cells were used to perform the same experiments as RPMI 8226 cells.

\subsection{Apoptosis and CCK8 Assay}

RPMI 8226 cells or NIH-3T3 cells were seeded into cell culture plates at a density of $5 \times 10^{5}$ cells /well. After $24 \mathrm{~h}$ of culture, different PTX formulations including Taxol, NPsPTX, and CNPs-PTX were applied with $100 \mathrm{ng} / \mathrm{mL}$ PTX per well as the final concentration. Cells without any drug treatment were served as control group. After drug treatment for $24 \mathrm{~h}$, cells from each group were collected and stained according to the Annexin VFITC apoptosis detection kit and followed by quantitative analysis using flow cytometry (Beckman, Kraemer Boulevard Brea, CA 92821, USA). In addition, RPMI 8226 cells or NIH3 T3 cells were also seeded into 96-well cell culture plates at a density of $5 \times 10^{3}$ cells/well; 24 h later, different PTX formulations including Taxol, NPs-PTX, and CNPs-PTX were applied with a series of PTX concentration from 1 to $200 \mathrm{ng} / \mathrm{mL}$ for $24 \mathrm{~h}$ culture. Then, the CCK8 reagent was added and incubated for $2 \mathrm{~h}$. The absorbance at $420 \mathrm{~nm}$ of each well was measured by a microplate reader (Tecan Safire 2, männedorf, Switzerland) and IC50 were calculated by GraphPad Prism 7.0.

\subsection{In Vivo Imaging}

It has been previously reported that fibroblasts from MM patients could drive the proliferation of RPMI 8226 cells as compared with fibroblasts from healthy donors. RPMI 8226 cells could also promote the proliferation of fibroblasts. They found that MM cells and fibroblasts could interact with each other to drive the growth of myeloma [20]. To improve the success rate of deploying nude mice to develop MM mouse models and better simulate disease conditions, MM-bearing nude mice models were established by subcutaneous co-injection of $5 \times 10^{6}$ RPMI 8226 cells and $2 \times 10^{6}$ NIH-3T3 cells in $100 \mu \mathrm{L}$ of PBS (0.01 M, pH = 7.4), which could consistently induce the formation of tumor xenograft within three weeks. As a comparison, nude mice that received the same amount of RPMI 8226 cells could not get an obvious xenograft until 4 weeks, and some even failed to induce the formation of xenograft (data not shown). When the diameter of the tumor reached $8 \mathrm{~mm}$, the MM-bearing mice models received a tail vein injection of DiR-labeled NPs or CNPs with the dose of DiR $0.5 \mathrm{mg} / \mathrm{kg}$. The mice models were imaged in vivo $24 \mathrm{~h}$ post DiR-labeled NPs administration by the In Vivo IVIS spectrum imaging system (PerkinElmer, USA). Then, $24 \mathrm{~h}$ post-drug administration, the mice were sacrificed and subjected to perfusion with $4 \%$ paraformaldehyde. Then, tumor tissues were collected, and the corresponding fluorescence signals ex vivo were also analyzed by the in vivo IVIS spectrum imaging system. 


\subsection{In Vivo Distribution}

MM-bearing nude mice models were injected with coumarin-6-labeled NPs and CNPs at the dose of coumarin- $60.05 \mathrm{mg} / \mathrm{kg}$. Then, $12 \mathrm{~h}$ later, the mice were sacrificed and perfused with $4 \%$ paraformaldehyde, and tumor tissues were prepared for frozen slices with a thickness of $20 \mu \mathrm{m}$. Immunofluorescence staining was performed as elsewhere described [9]. The vessels, MM tumor parenchymal cells, and CAFs were stained with CD31 rabbit polyclonal, CD138 rabbit monoclonal, and $\alpha$-SMA rabbit monoclonal primary antibody (1:100) at $4{ }^{\circ} \mathrm{C}$ overnight respectively, and then further stained with Alexa fluor 647 Affinipure goat anti-rabbit IgG secondary antibody (1:100) for $1 \mathrm{~h}$ at room temperature. After the cell nucleus were stained by Hoechst $33342(1 \mu \mathrm{g} / \mathrm{mL})$ at room temperature for $10 \mathrm{~min}$, the slices were mounted in Dako fluorescent mounting medium, captured under confocal microscopy (ZEISS, 710, LSM, wetzlar, Germany) and analyzed by ImageJ.

\subsection{Anti-Myeloma Study In Vivo}

MM-bearing nude mice models were established as described above. When the diameter of the tumor reached around $5 \mathrm{~mm}$, the mice were randomly divided into four groups $(n=5)$, including the control group treated with saline, the Taxol group, the NPs-PTX group, and the CNPs-PTX group with the dose of PTX $5 \mathrm{mg} / \mathrm{kg}$ for each time. Treatment was continued five times every three days through tail vein administration. The tumor size and body weight were measured every three days during the experiment. The tumor volumes were calculated using the following formula:

$$
V=\frac{1}{2} \times a \times b^{2}
$$

where $\mathrm{a}$ and $\mathrm{b}$ indicated the maximum and minimum diameters of the tumor, respectively. The tumor size and body weight were recorded for one more time after five cycles of treatments. When the whole experiment ended, tumors from all mice models were collected, and the weight of tumors was measured. Tumors were fixed with $4 \%$ paraformaldehyde, imbedded in paraffin, and sectioned at $5 \mu \mathrm{m}$ for terminal dUTP-mediated nick-end-labeling (TUNEL) staining. The tumor slices of TUNEL staining were observed under the fluorescence microscope (Leica, Germany) at $200 \times$ magnification, respectively. Tumor growth inhibition rates (TGIR) based on tumor size $\left(T_{G I R_{V}}\right)$ and tumor weight $\left(T G I R_{W}\right)$ were calculated using the following formulas, respectively:

$$
\begin{gathered}
\operatorname{TGIR}_{V}=\frac{v_{c}-v_{t}}{v_{c}} \\
\operatorname{TGIR}_{V}=\frac{w_{c}-w_{t}}{w_{c}} .
\end{gathered}
$$

In these formulas, $V_{c}$ and $V_{t}$ indicated the tumor volume in the control group and the treatment group, respectively; $W_{c}$ and $W_{t}$ indicated the tumor weight in the control group and the treatment group, respectively.

\subsection{Statistical Analysis}

All data were presented as mean \pm SD (standard deviation). Statistical comparisons were performed with an unpaired Student's t-test for two groups' comparison. A probability $(p)$ value $<0.05$ was considered statistically significant.

\section{Results and Discussions}

\subsection{Synthesis and Characterization of CNPS}

To develop a dual-targeting drug delivery system using PDGFR- $\beta$ in myeloma tissues as the therapeutic target, a cycle peptide with a special affinity for PDGFR- $\beta[19,21]$ was selected as the targeting moiety in our study, which is usually relatively more stable than other types of targeting moieties such as antibodies or proteins with much higher 
molecular weight [13]. As shown in Figure 2, the particle sizes of NPs and CNPs were about $100 \mathrm{~nm}$. The size and zeta potential of the NPs increased slightly after the cyclic peptide was attached. This is consistent with some previous reports, which also showed that peptide modification did not significantly affect the size and zeta potential of conventional polymers NPs [22]. Both NPs and CNPs were negatively charged.The negative charge was mainly because of the negative charge of carboxyl end groups from COOH-PEG-PLA [23]. In addition, the isoelectric point of the cyclic peptide is 4.59 and negatively charged. The cyclic peptide modification did not significantly affect the zeta potential of NPs, the reason for which might be the number of peptide moiety on the surface of NPs being around 107, which might not be sufficient to affect the zeta potential of nanoparticles [18]. The TEM photos showed that both NPs and CNPs were of smooth surface and regular size, and they were slightly smaller than those measured with a dynamic light scattering method (Figure 2C,D). No significant particle size changes were observed within a week after both NPs and CNPs were dispersed in 5\% FBS and stored at $4{ }^{\circ} \mathrm{C}$ (Figure S1). Under our experimental conditions (molar ratio of the carboxyl group to amino group $=3: 1$, reaction time $=4 \mathrm{~h}$ ), the concentration of free cyclic peptide unconjugated to nanoparticles were below the detection baseline by HPLC, which indicated that almost all the cyclic peptides have been successfully conjugated to nanoparticles. The encapsulation of coumarin-6, DIR, or PTX into NPs exerts a slight effect on the particle size and the zeta potential of both NPs and CNPs (Figure S2).
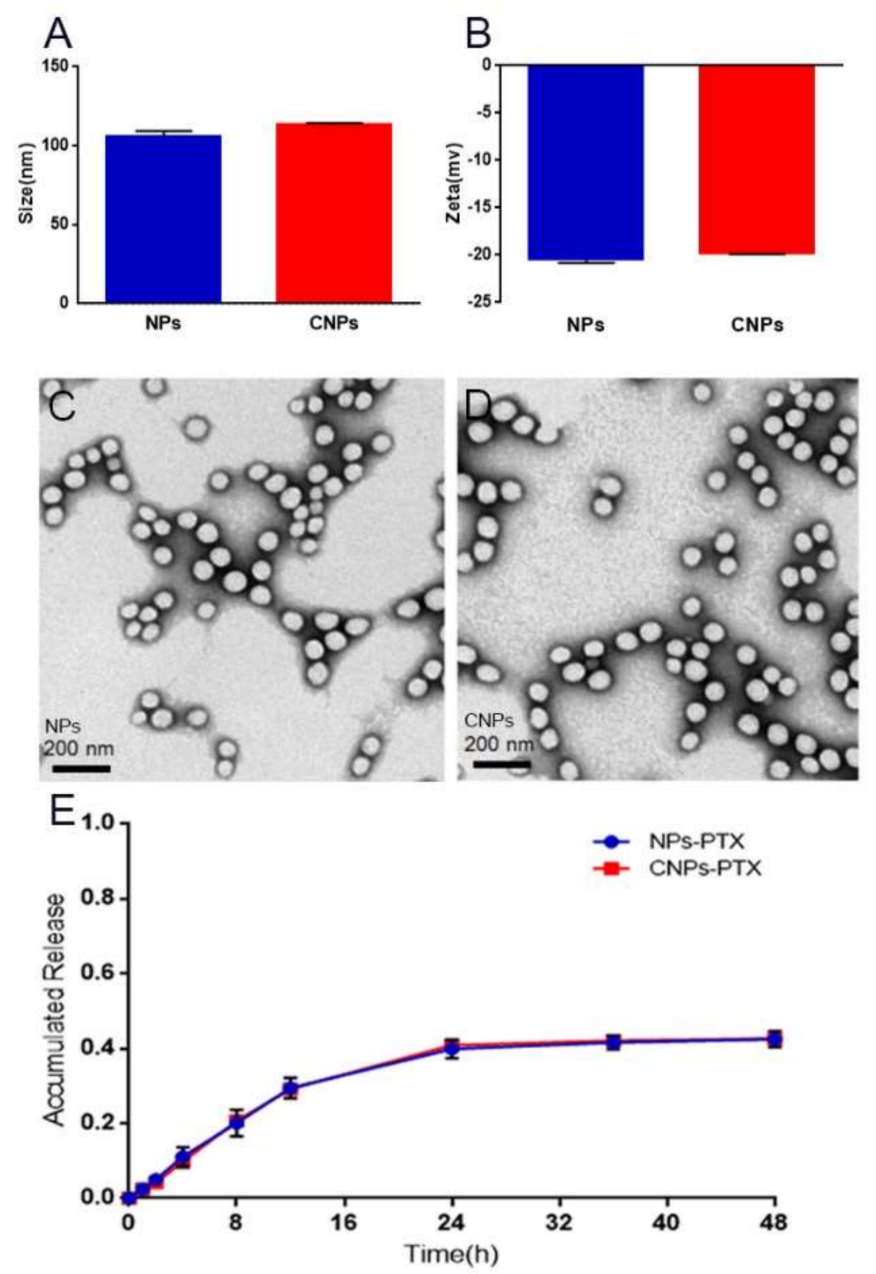

Figure 2. Characterization of cyclic peptide-modified nanoparticles (CNPs). Size distribution (A) and zeta potentials (B) of NPs and CNPs. Representative TEM image of NPs (C) and CNPs (D) (scale bar: $200 \mathrm{~nm}$ ). Paclitaxel (PTX) release curve in vitro (E). 
The LC values of NPs-PTX and CNPs-PTX were $5.58 \pm 0.01 \%(n=3)$ and $4.05 \% \pm 0.12$ $(n=3)$, respectively. The EE values of PTX in NPs-PTX and CNPs-PTX were $37.62 \% \pm 1.22$ $(n=3)$ and $32.55 \% \pm 0.92(n=3)$, respectively. The in vitro release profiles of PTX from both nanotherapeutics showed a similar biphasic pattern (Figure 2E), indicating that cyclic peptide modification did not significantly affect the in vitro release behavior of PTX from NPs. The sizes of these fluorescence tracker-labeled or drug-loaded NPs and CNPs are around $100 \mathrm{~nm}$ and fully meet the requirements of the drug delivery system for in vivo research as previously reported [18], which will be further used in subsequent experiments to assess its myeloma dual-targeting ability and anti-myeloma effect.

\subsection{Cellular Uptake Experiment}

To investigate the dual-targeting ability of CNPs, NIH-3T3 fibroblasts and RPMI 8226 myeloma cells, which have a high expression of PDGFR- $\beta$ molecule as reported [16], were selected as in vitro cell models for cellular uptake experiments in the present study. As shown in Figure 3, the CNPs group showed a much stronger signal in both RPMI 8226 cells and NIH-3T3 cells than the NPs group. The cellular uptake of CNPs by both types of cells could be inhibited to a certain degree by incubation with free cyclic peptide in advance. In addition, the uptake of CNPs could also be inhibited by coculture with PDGFR blocking agent suramin sodium (Figure S3). The semi-quantitative result obtained by ImageJ showed a similar result. These results demonstrated that the cyclic peptide could improve the cellular uptake of NPs by both NIH-3T3 cells and RPMI 8226 cells, which is probably through the interaction between the cyclic peptide modified on the surface of NPs and PDGFR- $\beta$ overexpressed by these two types of cells. The cellular uptake outcomes also indicated that drug-loaded CNPs might have higher cytotoxicity than the corresponding NP encapsulated with chemotherapeutic agents. 

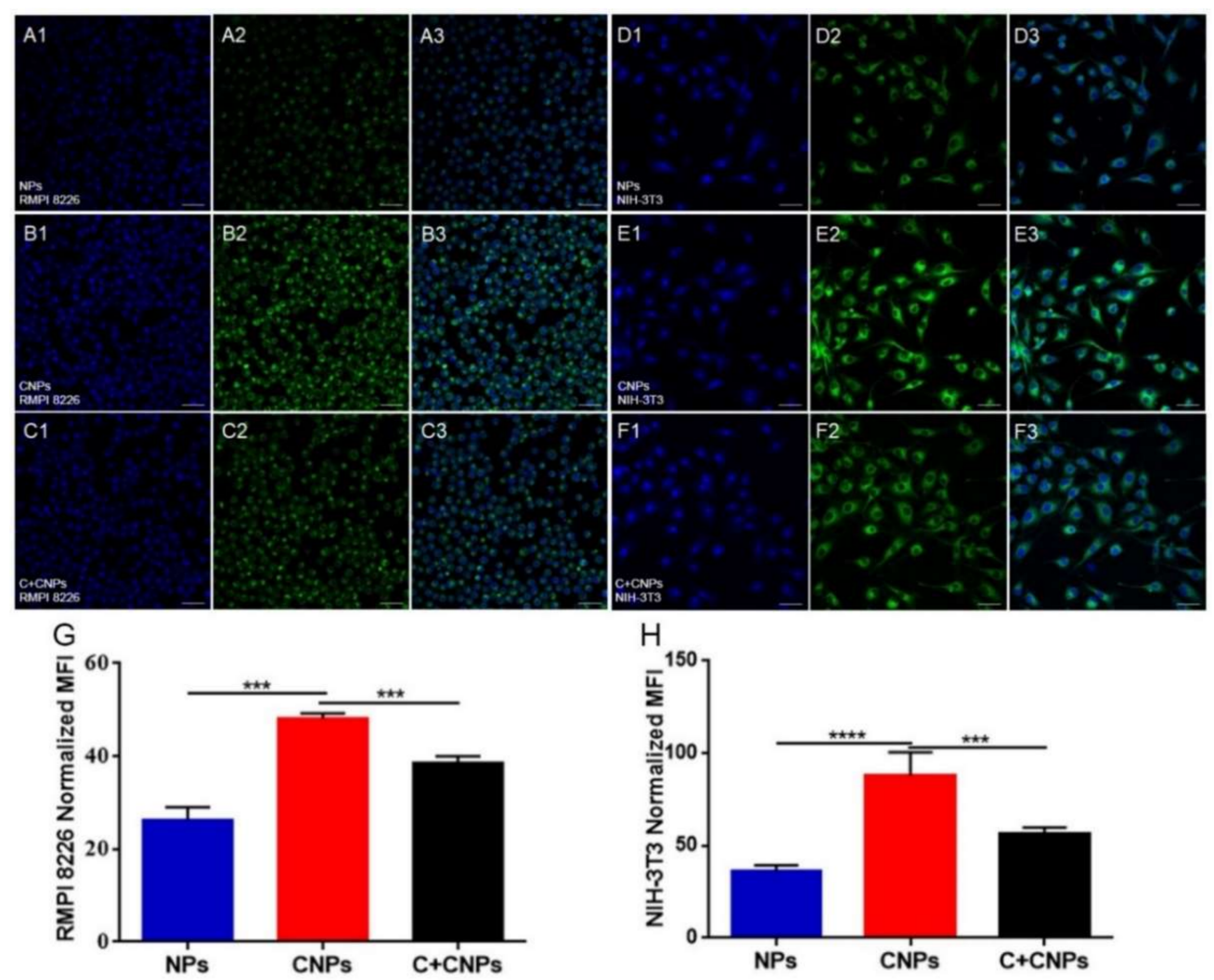

Figure 3. Cellular uptake experiments for RPMI 8226 cells (A-C,G) and NIH-3T3 cells (D-F,H). Fluorescence images for in vitro uptake of coumarin-6-labeled NPs (A,D), CNPs (B,E), and CNPs with free cyclic peptide preincubation $(\mathbf{C}, \mathbf{F})$, respectively. Image 3 was obtained by merging images 1 and 2 . The corresponding semi-quantitative results $(\mathbf{G}, \mathbf{H})$ were obtained using Image J software. Green indicated coumarin-6 labeled NPs or CNPs. Blue indicated cell nuclei. Original magnification: $200 \times{ }^{* * *} p<0.001,{ }^{* * * *} p<0.0001$.

\subsection{Apoptosis and CCK8 Assay}

To test our hypothesis mentioned above, classical chemotherapeutics PTX with favorable lipophilicity was used as the model drug, while the cytotoxic effect of different PTX formulations to RPMI 8226 cells and NIH-3T3 cells in vitro was determined by apoptosis and CCK8 assay. Different PTX formulations, including Taxol, NPs-PTX, and CNPs-PTX were added to the cells, incubated for $24 \mathrm{~h}$, and followed by flow cytometry detection of cell apoptosis. The results showed that CNPs-PTX could induce more cell apoptosis than NPs-PTX and Taxol for both cell types (Figure 4). The total apoptosis rate of RPMI 8226 cells in the CNPs-PTX group is $46.36 \pm 0.75 \%$, which is much higher than $42.03 \pm 0.70 \%$ and $36.83 \pm 1.12 \%$ in NPs-PTX group and Taxol group, respectively. For NIH-3T3 cells, the apoptosis rate is $63.31 \pm 1.36 \%$ in the CNPs-PTX group, which is also much higher than $53.23 \pm 2.04 \%$ and $50.17 \pm 2.19 \%$ in NPs-PTX group and Taxol group, respectively. The CCK8 assay showed that all PTX formulations exhibited inhibitory effects to the proliferation of RPMI 8226 cells and NIH-3T3 cells. At various concentration points, CNP-PTX exhibited the strongest inhibitory effect on both cells (Figure S4 and Table S1). The results of cytotoxicity assay were consistent to that of the apoptosis assay. All these results were consistent with the results of cellular uptake, indicating that cyclic peptide modification can enhance cellular uptake and therefore cytotoxicity, further confirming the dual-targeting ability of CNPs-PTX. 

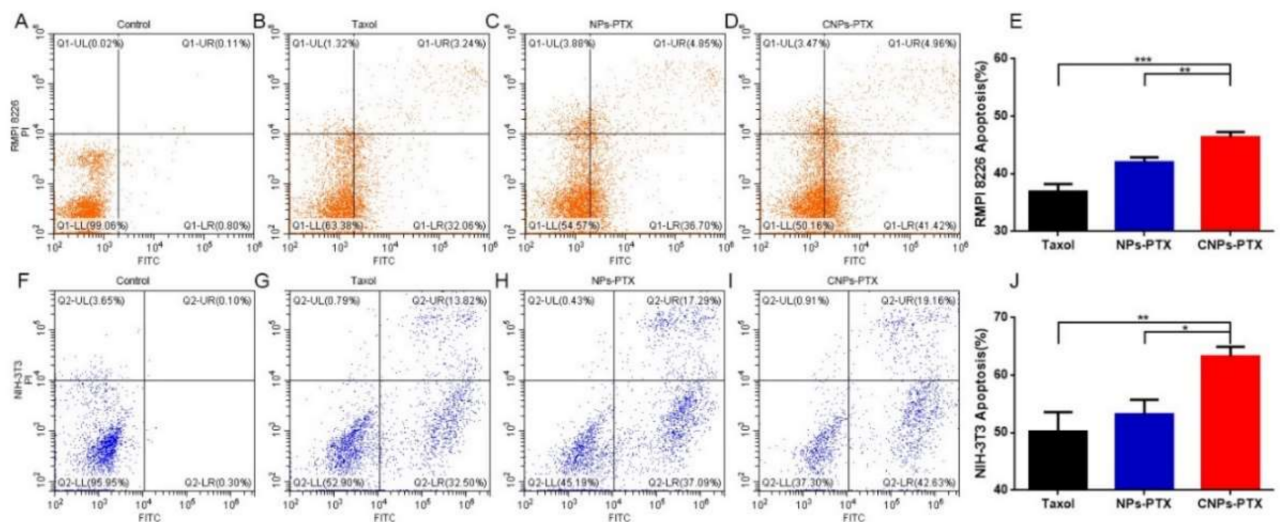

Figure 4. Cytotoxic assay. Representative flow cytometer images of RPMI 8226 cells and NIH-3T3 cells $24 \mathrm{~h}$ after different drug treatment Taxol (B,G), NPs-PTX (C,H), CNPs-PTX (D,I) at the dose of PTX $100 \mathrm{ng} / \mathrm{mL}$. Samples without any drug treatment served as control (A,F). The flow cytometry quantitative results for RPMI 8226 cells (E) and NIH-3T3 cells $(\mathrm{J}) .^{*} p<0.05,{ }^{* *} p<0.01,{ }^{* * *} p<0.001$.

\subsection{In Vivo Imaging}

In vivo imaging was performed to understand the targeting ability of CNPs to myeloma in vivo. The whole-body image acquired $24 \mathrm{~h}$ post-injection showed that the fluorescence signal intensity in the tumor site of the CNPs group was much higher than that of the NPs group (Figure 5A). Similarly, the fluorescence intensity of the tumor in the CNPs group ex vivo was also higher than that in the NPs group (Figure $5 \mathrm{~B}$ ), and the ex vivo semi-quantitative results showed that the fluorescence signal intensity of the tumor in the CNPs group was 2.3 times that of the NPs group (Figure 5C).
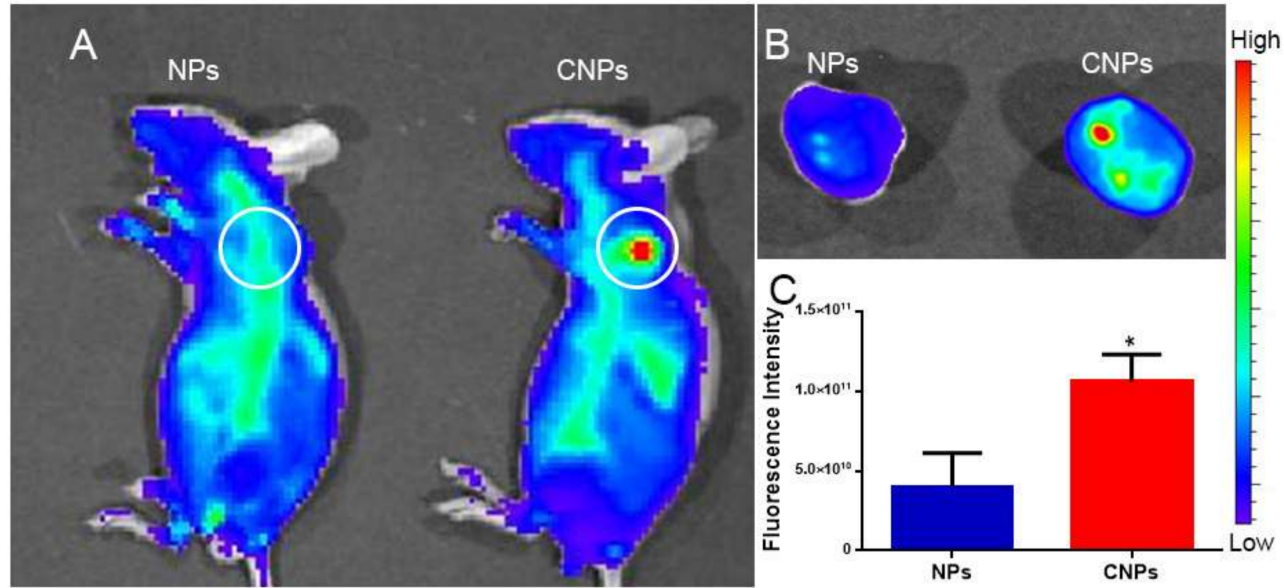

Figure 5. In vivo imaging. In vivo imaging of tumor-bearing mice $24 \mathrm{~h}$ after $1,1^{\prime}$-dioctadecyl-3,3, $3^{\prime}, 3^{\prime}$ tetramethylindo-tricarbocyanineiodide (DiR)-loaded NPs and CNPs treatment (A). Ex vivo imaging of tumors (B) and the corresponding semi-quantitative result $(\mathbf{C})$. White circle: tumor site. ${ }^{*} p<0.05$.

\subsection{In Vivo Distribution}

Since the overall accumulation of nanotherapeutics in tumor tissues alone did not ensure optimal therapeutic efficacy, a homogeneous distribution pattern of nanotherapeutics within tumor tissues might be more critical for the final performance of nanotherapeutics [24,25]. Nanotherapeutics distribution within myeloma was detected by immunofluorescence staining followed by confocal microscopy analysis. To track NPs in vivo, green fluorescence tracker coumatin-6 was used to label NPs. Results of immunofluorescence staining showed only a few NPs localized in the vicinity of tumor vessels. In comparison, CNPs are not only abundantly deposited nearby tumor vessels but also penetrate tumor tissues to reach those regions far away from tumor vessels (Figure 6A,B); the quantitative 
evaluation was also performed to show that the signal from CNPs was much higher than that from conventional NPs (Figure 6D), while there was no significant difference between the NPs and CNPs group in regard to the signal from tumor vessels (Figure 6C), which suggested that CNPs could distribute more widely in tumor tissues than NPs. Furthermore, more CNPs were found to be colocalized with myeloma cells or CAFs than NPs (Figures 7, 8 and S5), which suggested that more CNPs could be uptaken by both CAFs and myeloma cells as compared with NPs. These results compared well to the results of in vitro uptake (Figure 3) and in vivo fluorescence imaging experiments (Figure 5), which altogether validated the dual-targeting ability of CNPs in vitro and in vivo. Therefore, more drugs can be delivered by CNPs to PDGFR- $\beta$ overexpressed myeloma cells and CAFs, and better therapeutics benefit can be predicted when PTX was loaded.
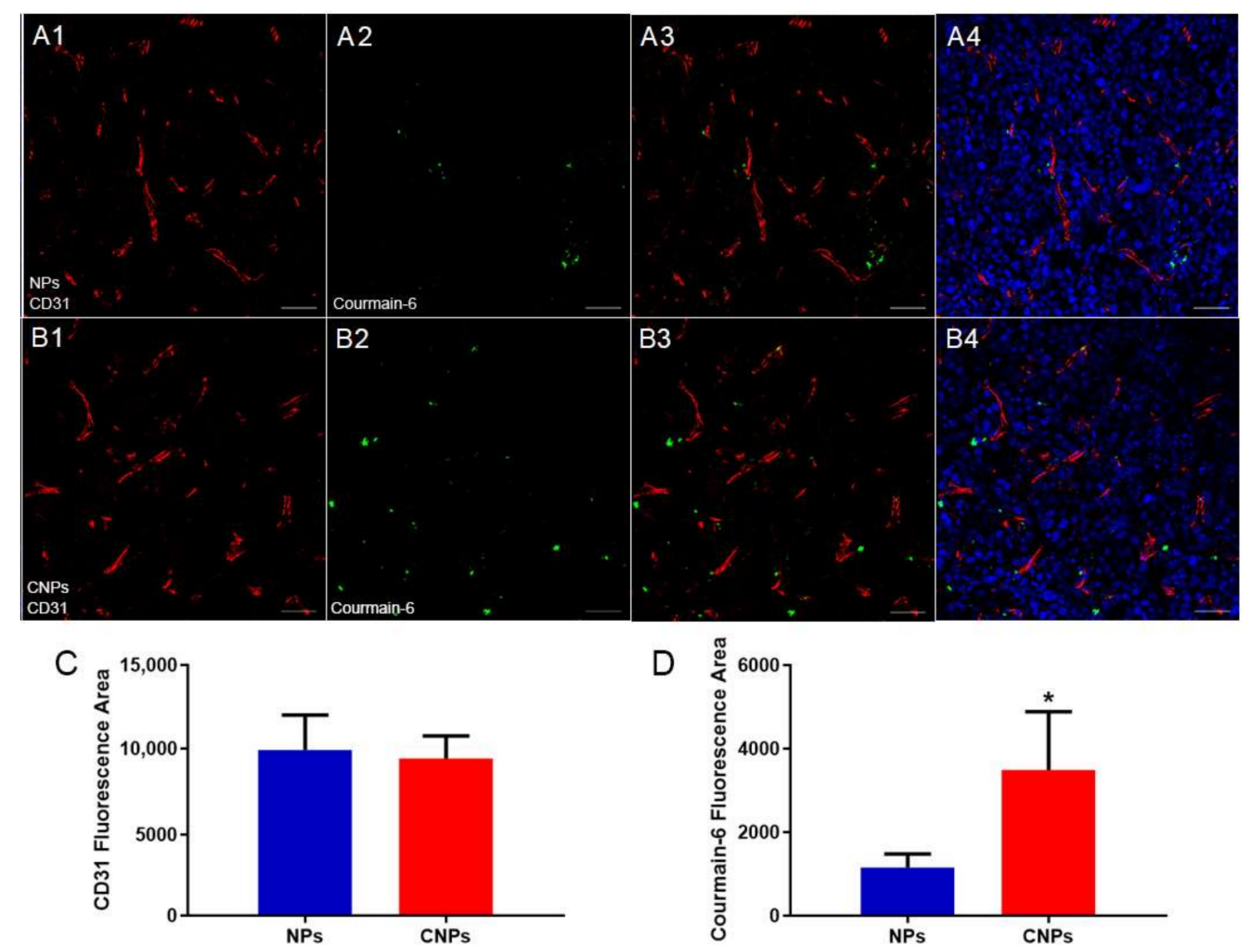

Figure 6. In vivo distribution experiment. The images of distribution of NPs (A1-A4) and CNPs (B1-B4) in tumor tissues $24 \mathrm{~h}$ post-injection of courmain-6 labeled NPs or CNPs. Image 3 was merged by images 1 and 2 . Image 4 was merged by nucleus and image 3 . Semiquantitative results of signal of vessels indicated by CD31 fluorescence area $(C)$ and signal of NPs and CNPs indicated by coumarin- 6 fluorescence area (D) analyzed by ImageJ $(n=3)$. ${ }^{*} p<0.05$. Green indicated courmain-6-labeled NPs or CNPs. Red indicated CD31-labeled tumor vessels. Blue indicated cell nucleus. Original magnification: $200 \times$. Scale bars, $50 \mu \mathrm{m}$. 


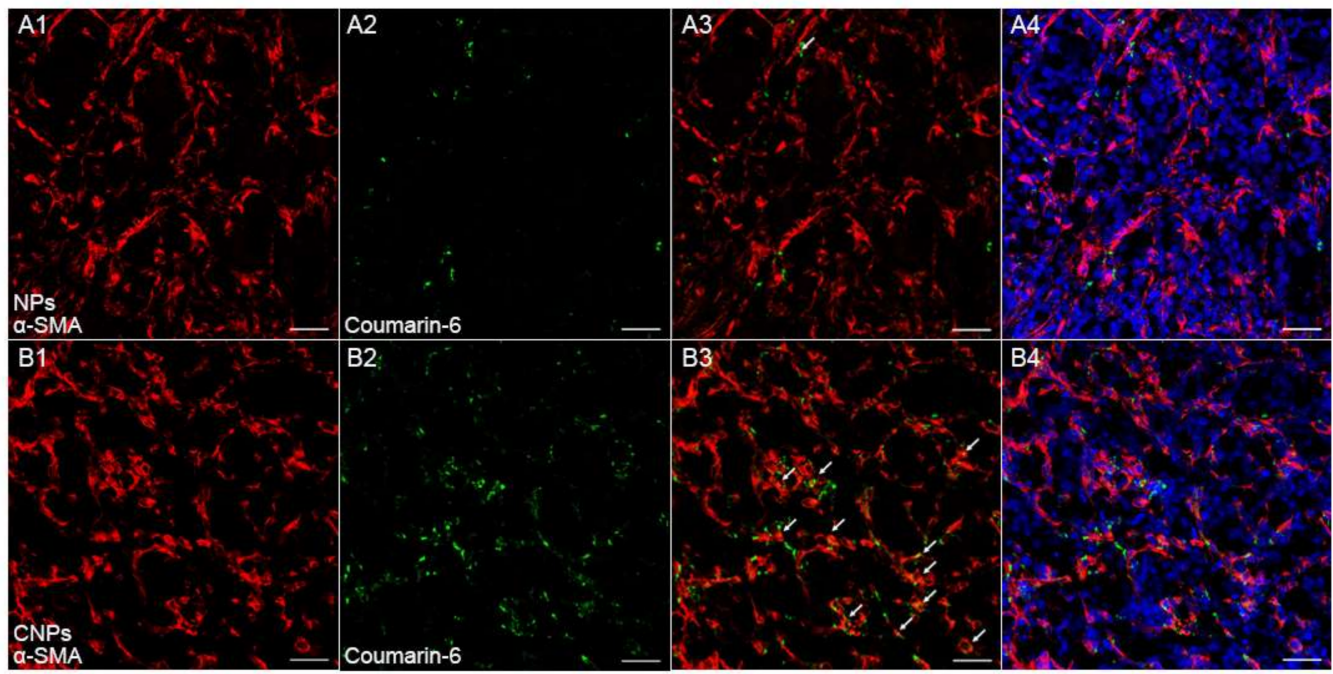

Figure 7. In vivo co-localization of NPs (A) or CNPs (B) with CAFs. Image 3 was the merged by images 1 and 2. Image 4 was merged by nucleus and image 3 . Red indicated CAFs labeled by $\alpha$-smooth muscle actin ( $\alpha$-SMA). Green indicated coumarin-6 labeled NPs or CNPs. Blue indicated cell nuclei. The arrow indicated the co-localization of coumarin-6 labeled NPs or CNPs and CAFs. Original magnification: $200 \times$. Scale bars, $50 \mu \mathrm{m}$.

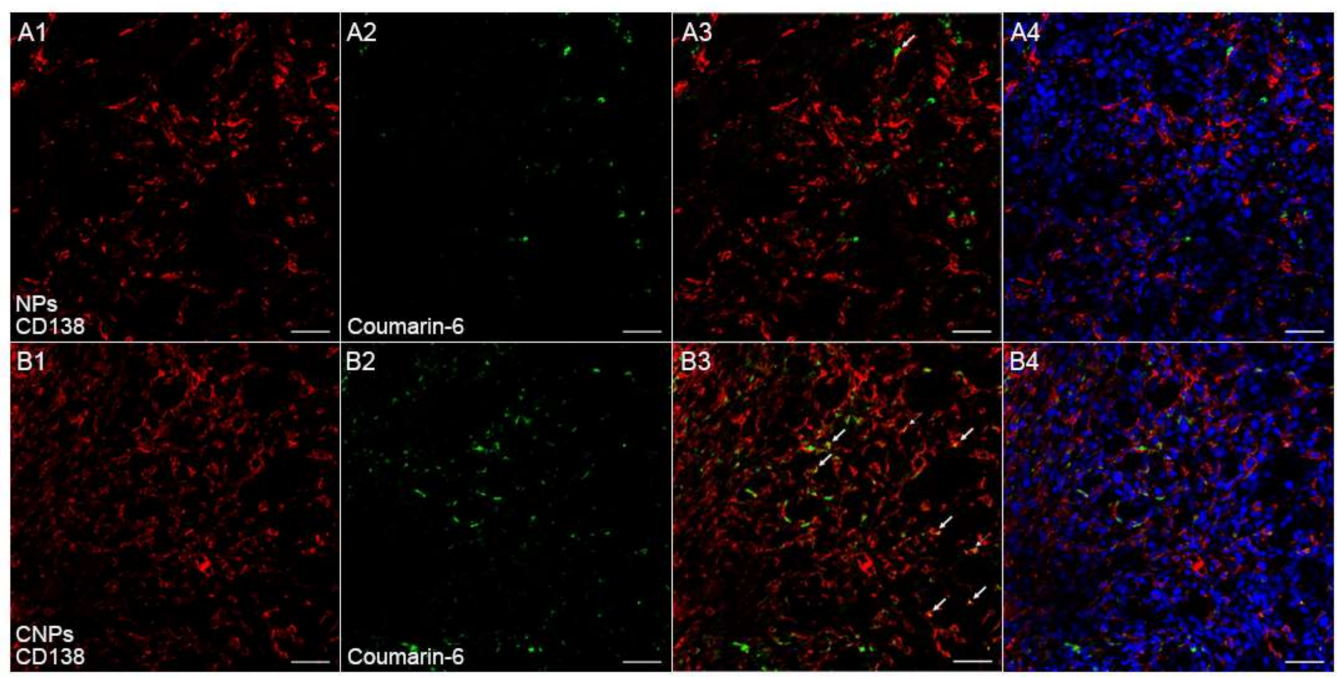

Figure 8. In vivo co-localization of NPs (A) or CNPs (B) with myeloma cells. Image 3 was created by merging images 1 and 2 . Image 4 was created by merging the nucleus and image 3 . Red indicated myeloma cells labeled by CD138. Green indicated coumarin-6-labeled NPs or CNPs. Blue indicated cell nuclei. The arrow indicated the co-localization of coumarin-6 labeled NPs or CNPs and myeloma cells. Original magnification: $200 \times$. Scale bars, $50 \mu \mathrm{m}$.

\subsection{Anti-Myeloma Study In Vivo}

To understand the therapeutic efficacy of CNPs-PTX for myeloma treatment, a pharmacodynamics experiment was carried out. As shown in Figure 9A, the tumor growth was significantly inhibited in the CNPs-PTX group compared with the other groups. Taxol and NPs-PTX had only mild therapeutic effects compared with the control group. The TGIRv and TGIR $w$ for the CNPs-PTX group were $64.9 \%$ and $76.5 \%$, which was much higher than $35.5 \%$ and $41.1 \%$ in the NPs-PTX group and $17.8 \%$ and $29.0 \%$ in the Taxol group (Figure 9C,D). After five cycles of treatment, the tumors were removed for TUNEL staining. The green fluorescence was much more in the CNPs-PTX group than that of the other three groups (Figure S6), indicating that the most severe tumor cell apoptosis occurred in this 
group, which accorded well to the tumor inhibitive curve. There were no obvious changes in the body weight of mice models during the experiment (Figure 9B), indicating that the PTX dose in our study is safe for mice. Overall, the best anti-myeloma effect was found in the CNPs-PTX group, which is probably due to its dual-targeting ability to both CAFs and myeloma cells.
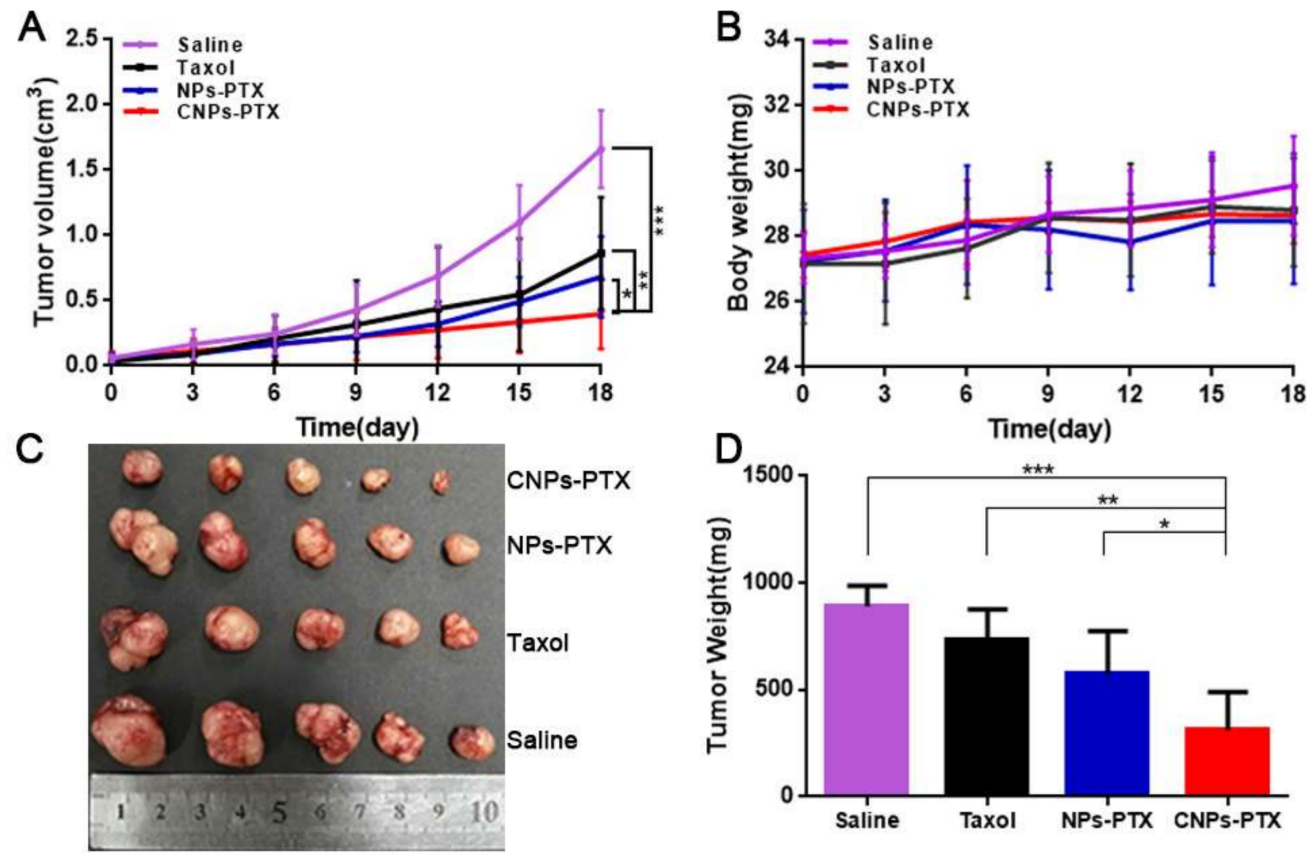

Figure 9. In vivo anti-myeloma efficacy of paclitaxel (PTX)-loaded poly(ethylene glycol)-poly(lactic acid) nanoparticles (NPs) with a cyclic peptide (CNPs-PTX). Tumor growth curve (A) and weight change curve of mice models during the experiment (B). Gross appearance of tumors $(\mathbf{C})$ and tumor weight (D) at the study end point. ${ }^{*} p<0.05,{ }^{* *} p<0.01,{ }^{* * *} p<0.001$.

Varying degrees of success have been achieved for tumor drug delivery based on a dual-targeting strategy as previously reported. In one study, fusion protein EGFP-EGF1 with high affinity for tissue factor (TF) has been selected as the targeting moiety, and TF overexpressed by different cell types, including tumor parenchyma cells, TAFs, and tumor-associated endothelial in glioma and lung cancer, was utilized as the therapeutic target $[13,26]$. Some other studies also utilized two different targeting moieties to conquer different obstacles hindering tumor drug delivery $[27,28]$. These dual-targeting nanotherapeutics are less ideal because of the relative instability of high molecular protein and the synthetic complex of conjugating two different targeting moieties. As a comparison, our single cyclic peptide modified dual-targeting CNPs have the advantages of more stability of targeting moiety and synthetic simplicity of conjugating only a single targeting moiety.

This strategy opened a new avenue for myeloma treatment by dual targeting both CAFs (the soil) and myeloma cells (the seed) simultaneously. Since CAFs produce a lot of cytokines to drive myeloma progression and are closely associated with a tumor immune inhibitive state $[20,29]$, the changes of immune state within a myeloma site deserves further study to understand whether the therapeutic effect was immune-related or not, which requires a mouse-derived $\mathrm{MM}$ cell line and immune competent recipient mice to develop a suitable mouse model. In addition, PDGFR- $\beta$ was also overexpressed in various other types of tumor parenchymal cells such as breast cancer cells and colon carcinoma cells $[6,15,30]$; the dual-targeting nanotherapeutics modified with the cyclic peptide might provide a new avenue for the treatment of other solid tumors as well. 


\section{Conclusions}

In this study, we exploited a cyclic peptide with high affinity with PDGFR- $\beta$ as a targeting moiety to establish a dual-targeting drug delivery system that could not only improve the cellular uptake of CNPs by myeloma cells and CAFs but also induce more cell apoptosis of both types of cells when PTX was loaded. In vivo tests showed dualtargeting CNPs exhibited significantly stronger myeloma accumulation, myeloma targeting, and enhanced chemotherapeutic effect of PTX as compared with those of other groups in myeloma-bearing mouse models. Altogether, it is the first time that a dual-targeting strategy was applied for myeloma treatment, and these promising outcomes suggested that the dual-targeting drug delivery system might exhibit great potential for myeloma treatment in clinical applications.

Supplementary Materials: The following are available online at https://www.mdpi.com/1999-4 923/13/2/274/s1, Figure S1: Size (A) and PDI (B) of NPs and CNPs in 10\% FBS during one-week storage at $4{ }^{\circ} \mathrm{C} .(n=3)$, Figure S2: Characterization of different types of NPs and CNPs. A. Size of Coumarin-6-, DiR- and PTX-loaded NPs and CNPs. B. Zeta potential of Coumarin-6-, DiR- and PTX-loaded NPs and CNPs. $(n=3)$, Figure S3: CNPs uptake by RPMI 8226 cells $(A, B, C)$ and NIH$3 T 3$ cells $(D, E, F)$ treated with (B\&E) or without (A\&D) PDGFR- $\beta$ blocking agent suramin sodium analyzed by microscopy $(\mathrm{A}, \mathrm{B}, \mathrm{D}, \mathrm{E})$ and Image $(\mathrm{C} \& \mathrm{~F})$. Green indicated coumarin-6 labeled CNPs. Blue indicated cell nuclei. Original magnification: 200×, Figure S4: In vitro cytotoxicy of Taxol, NP-PTX and CNP-PTX against RPMI 8226 cells (A) and NIH-3T3 cells (B) by CCK8 assay, Figure S5: In vivo co-localized study of coumarin-6 labeled NPs $(\mathrm{A}, \mathrm{E}, \mathrm{C}, \mathrm{G})$ or $\mathrm{CNPs}(\mathrm{B}, \mathrm{F}, \mathrm{D}, \mathrm{H})$ with fibroblasts $(\mathrm{C}, \mathrm{G}, \mathrm{D}, \mathrm{H})$ or myeloma cells $(\mathrm{A}, \mathrm{E}, \mathrm{B}, \mathrm{F})$ observed by confocal $(\mathrm{A}, \mathrm{B}, \mathrm{C}, \mathrm{D})$ and analyzed by Image and origin $(\mathrm{E}, \mathrm{F}, \mathrm{G}, \mathrm{H})$. The signal intensity in the histogram is obtained from the line randomly put in the corresponding figure, Figure S6. TUNEL staining of tumor tissue sections from MM bearing mice model of in vivo anti-myeloma study (left to right: Saline, Taxol, NPs-PTX, and CNPs-PTX). Table S1: IC50 of RPMI8226 and NIH-3T3 by Taxol, NP-PTX and CNP-PTX calculated by GraphPad Prism 7.0 based on CCK8 assay.

Author Contributions: Conceptualization, Z.P., B.Z. and Y.H.; methodology, H.W. and B.Z.; software, T.J. and C.L.; validation, Z.P., B.Z. and Y.H.; formal analysis, H.W., H.L. and C.S.; investigation, H.W.; resources, B.Z.; data curation, Z.P.; writing—original draft preparation, H.W., H.L. and C.S.; writing-review and editing, Z.P. and B.Z.; visualization, A.X. and Y.Y.; supervision, Z.P.; project ad-ministration, Y.H.; funding acquisition, B.Z. All authors have read and agreed to the published version of the manuscript.

Funding: This research was funded by the National Natural Science Foundation of China, grant number 81600175, 81773283, 81670197, 81974007.

Institutional Review Board Statement: The study was conducted according to the guidelines of the Declaration of Helsinki, and approved by the ethics committee of Fudan University. (protocol code 2017-03-YJ-PZQ-01 and 1 March 2017).

Informed Consent Statement: Not applicable.

Data Availability Statement: The data presented in this study are available in Supplementary Materials: https:/ /www.mdpi.com/1999-4923/13/2/274/s1.

Acknowledgments: This work was supported by the National Natural Science Foundation of China (81600175, 81773283, 81670197, 81974007), Integrated Innovative Team for Major Human Diseases Program of Tongji Medical College, HUST, Clinical Research Physician Program of Tongji Medical College, HUST, and Fundamental Research Funds For the Central Universities.

Conflicts of Interest: The authors disclose no potential conflicts of interest.

\section{References}

1. Röllig, C.; Knop, S.; Bornhäuser, M. Multiple myeloma. Lancet 2015, 385, 2197-2208. [CrossRef]

2. Dimopoulos, M.A.; Oriol, A.; Nahi, H.; San-Miguel, J.; Bahlis, N.J.; Usmani, S.Z.; Rabin, N.; Orlowski, R.Z.; Komarnicki, M.; Suzuki, K.; et al. Daratumumab, lenalidomide, and dexamethasone for multiple myeloma. Engl. J. Med. 2016, 375, 1319-1331. [CrossRef] [PubMed] 
3. Ludwig, H.; Delforge, M.; Facon, T.; Einsele, H.; Gay, F.; Moreau, P.; Avet-Loiseau, H.; Boccadoro, M.; Hajek, R.; Mohty, M.; et al. Prevention and management of adverse events of novel agents in multiple myeloma: A consensus of the European myeloma network. Leukemia 2018, 32, 1542-1560. [CrossRef]

4. Ribatti, D.; Moschetta, M.; Vacca, A. Microenvironment and multiple myeloma spread. Thromb. Res. 2014, 133, S102-S106. [CrossRef]

5. Loi, M.; Marchiò, S.; Becherini, P.; Di Paolo, D.; Soster, M.; Curnis, F.; Brignole, C.; Pagnan, G.; Perri, P.; Caffa, I. Combined targeting of perivascular and endothelial tumor cells enhances anti-tumor efficacy of liposomal chemotherapy in neuroblastoma. J. Control. Release 2010, 145, 66-73. [CrossRef]

6. Prakash, J.; De Jong, E.; Post, E.; Gouw, A.S.H.; Beljaars, L.; Poelstra, K. A novel approach to deliver anticancer drugs to key cell types in tumors using a PDGF receptor-binding cyclic peptide containing carrier. J. Control. Release 2010, 145, 91-101. [CrossRef] [PubMed]

7. Ciavarella, S.; Laurenzana, A.; De Summa, S.; Pilato, B.; Chillà, A.; Lacalamita, R.; Minoia, C.; Margheri, F.; Iacobazzi, A.; Rana, A.; et al. u-PAR expression in cancer associated fibroblast: New acquisitions in multiple myeloma progression. BMC Cancer 2017, 17, 215. [CrossRef]

8. Zhang, B.; Jiang, T.; Tuo, Y.; Jin, K.; Luo, Z.; Shi, W.; Mei, H.; Hu, Y.; Pang, Z.; Jiang, X.; et al. Captopril improves tumor nanomedicine delivery by increasing tumor blood perfusion and enlarging endothelial gaps in tumor blood vessels. Cancer Lett. 2017, 410, 12-19. [CrossRef] [PubMed]

9. Zhang, B.; Jin, K.; Jiang, T.; Wang, L.; Shen, S.; Luo, Z.; Tuo, Y.; Liu, X.; Hu, Y.; Pang, Z.; et al. Celecoxib normalizes the tumor microenvironment and enhances small nanotherapeutics delivery to A549 tumors in nude mice. Sci. Rep. 2017, 7, 1-12. [CrossRef]

10. Gradishar, W.J.; Tjulandin, S.; Davidson, N.; Shaw, H.; Desai, N.; Bhar, P.; Hawkins, M.; O'Shaughnessy, J. Phase III trial of nanoparticle albumin-bound paclitaxel compared with polyethylated castor oil-based paclitaxel in women with breast cancer. J. Clin. Oncol. 2005, 23, 7794-7803. [CrossRef] [PubMed]

11. O’Brien, M.E.R.; Wigler, N.; Inbar, M.; Rosso, R.; Grischke, E.; Santoro, A.; Catane, R.; Kieback, D.G.; Tomczak, P.; Ackland, S.P.; et al. Reduced cardiotoxicity and comparable efficacy in a phase III trial of pegylated liposomal doxorubicin $\mathrm{HCl}\left(\mathrm{CAELYX}^{\mathrm{TM}} /\right.$ Doxil $\left.^{\circledR}\right)$ versus conventional doxorubicin forfirst-line treatment of metastatic breast cancer. Ann. Oncol. 2004, 15, 440-449. [CrossRef]

12. Zhang, B.; Pang, Z.; Hu, Y. Targeting hemostasis-related moieties for tumor treatment. Thromb. Res. 2020, 187, 186-196. [CrossRef]

13. Zhang, B.; Jiang, T.; Ling, L.; Cao, Z.; Zhao, J.; Tuo, Y.; She, X.; Shen, S.; Jiang, X.; Hu, Y.; et al. Enhanced antitumor activity of EGFP-EGF1-conjugated nanoparticles by a multitargeting strategy. ACS Appl. Mater. Interfaces 2016, 8, 8918-8927. [CrossRef]

14. Kazlauskas, A. PDGFs and their receptors. Gene 2017, 614, 1-7. [CrossRef] [PubMed]

15. Primac, I.; Maquoi, E.; Blacher, S.; Heljasvaara, R.; Van Deun, J.; Smeland, H.Y.H.; Canale, A.; Louis, T.; Stuhr, L.; Sounni, N.E.; et al. Stromal integrin $\alpha 11$ regulates PDGFR $\beta$ signaling and promotes breast cancer progression. J. Clin. Investig. 2019, 129. [CrossRef]

16. Coluccia, A.M.L.; Cirulli, T.; Neri, P.; Mangieri, D.; Colanardi, M.C.; Gnoni, A.; Di Renzo, N.; Dammacco, F.; Tassone, P.; Ribatti, D.; et al. Validation of PDGFR $\beta$ and c-Src tyrosine kinases as tumor/vessel targets in patients with multiple myeloma: Preclinical efficacy of the novel, orally available inhibitor dasatinib. Blood 2008, 112, 1346-1356. [CrossRef]

17. Dong, Y.; Feng, S.-S. Methoxy poly(ethylene glycol)-poly(lactide) (MPEG-PLA) nanoparticles for controlled delivery of anticancer drugs. Biomaterials 2004, 25, 2843-2849. [CrossRef]

18. Zhang, B.; Sun, X.; Mei, H.; Wang, Y.; Liao, Z.; Chen, J.; Zhang, Q.; Hu, Y.; Pang, Z.; Jiang, X.; et al. LDLR-mediated peptide-22conjugated nanoparticles for dual-targeting therapy of brain glioma. Biomaterials 2013, 34, 9171-9182. [CrossRef] [PubMed]

19. Li, F.; Li, Q.-H.; Wang, J.-Y.; Zhan, C.-Y.; Xie, C.; Lu, W.-Y. Effects of interferon-gamma liposomes targeted to platelet-derived growth factor receptor-beta on hepatic fibrosis in rats. J. Control. Release 2012, 159, 261-270. [CrossRef]

20. Frassanito, M.V.; Rao, L.; Moschetta, M.; Ria, R.; Di Marzo, L.; De Luisi, A.; Racanelli, V.; Catacchio, I.; Berardi, S.; Basile, A.; et al. Bone marrow fibroblasts parallel multiple myeloma progression in patients and mice: In Vitro and In Vivo studies. Leukemia 2013, 28, 904-916. [CrossRef] [PubMed]

21. Bansal, R.; Tomar, T.; Östman, A.; Poelstra, K.; Prakash, J. Selective targeting of interferon $\gamma$ to stromal fibroblasts and pericytes as a novel therapeutic approach to inhibit angiogenesis and tumor growth. Mol. Cancer 2012, 11, 2419-2428. [CrossRef] [PubMed]

22. Zhang, B.; Zhang, Y.; Liao, Z.; Jiang, T.; Zhao, J.; Tuo, Y.; She, X.; Shen, S.; Chen, J.; Zhang, Q.; et al. UPA-sensitive ACPP-conjugated nanoparticles for multi-targeting therapy of brain glioma. Biomaterials 2015, 36, 98-109. [CrossRef]

23. Lu, W.; Zhang, Y.; Tan, Y.-Z.; Hu, K.-L.; Jiang, X.-G.; Fu, S.-K. Cationic albumin-conjugated pegylated nanoparticles as novel drug carrier for brain delivery. J. Control. Release 2005, 107, 428-448. [CrossRef]

24. Wong, C.; Stylianopoulos, T.; Cui, J.; Martin, J.D.; Chauhan, V.P.; Jiang, W.; Popović, Z.; Jain, R.K.; Bawendi, M.G.; Fukumura, D.; et al. Multistage nanoparticle delivery system for deep penetration into tumor tissue. Proc. Natl. Acad. Sci. USA 2011, 108, 2426-2431. [CrossRef] [PubMed]

25. Tong, R.; Chiang, H.H.; Kohane, D.S. Photoswitchable nanoparticles for In Vivo cancer chemotherapy. Proc. Natl. Acad. Sci. USA 2013, 110, 19048-19053. [CrossRef] [PubMed]

26. Zhang, B.; Wang, H.; Liao, Z.; Wang, Y.; Hu, Y.; Yang, J.; Shen, S.; Chen, J.; Mei, H.; Shi, W.; et al. EGFP-EGF1-conjugated nanoparticles for targeting both neovascular and glioma cells in therapy of brain glioma. Biomaterials 2014, 35, 4133-4145. [CrossRef] 
27. Gao, H.; Qian, J.; Cao, S.; Yang, Z.; Pang, Z.; Pan, S.; Fan, L.; Xi, Z.; Jiang, X.; Zhang, Q.; et al. Precise glioma targeting of and penetration by aptamer and peptide dual-functioned nanoparticles. Biomaterials 2012, 33, 5115-5123. [CrossRef] [PubMed]

28. Gao, H.; Yang, Z.; Cao, S.; Xiong, Y.; Zhang, S.; Pang, Z.; Jiang, X. Tumor cells and neovasculature dual targeting delivery for glioblastoma treatment. Biomaterials 2014, 35, 2374-2382. [CrossRef] [PubMed]

29. De Jaeghere, E.A.; Denys, H.G.; De Wever, O. Fibroblasts fuel immune escape in the tumor microenvironment. Trends Cancer 2019, 5, 704-723. [CrossRef]

30. Roskoski, R. The role of small molecule platelet-derived growth factor receptor (PDGFR) inhibitors in the treatment of neoplastic disorders. Pharm. Res. 2018, 129, 65-83. [CrossRef] 